\title{
Weak Breathing
}

National Cancer Institute

\section{Source}

National Cancer Institute. Weak Breathing. NCI Thesaurus. Code C87129.

Shallow inhalations and exhalations that indicate respiratory distress. 